\title{
Identification and management of frailty in the primary care setting
}

\author{
Marjan Abbasi MD, Darryl Rolfson MD, Amandeep S. Khera MD MPH, Julia Dabravolskaj MD MSc, Elsa Dent PhD, \\ Linda Xia BSc
}

Cite as: CMAJ 2018 September 24;190:E1134-40. doi: 10.1503/cmaj.171509

See related article at www.cmaj.ca/lookup/doi/10.1503/cmaj.181151

$\mathbf{F}$ railty is a dynamic state of heightened vulnerability to stressors. It is a multidimensional syndrome that places individuals at risk for adverse health outcomes, including falls, disability, admission to hospital and death. ${ }^{1}$ The prevalence of frailty rises with advancing age, from $16 \%$ in people older than 65 years to rates as high as $52 \%$ in those older than 85 years. ${ }^{2}$ It is associated with many comorbidities and is more common among women ${ }^{3}$ and individuals with lower socioeconomic status. ${ }^{4}$ Frailty is not an inevitable part of aging, although it is noted frequently during a person's last year of life. ${ }^{5}$ However, frailty is a challenge for modern geriatric medicine ${ }^{6}$ and for health services, because it is associated with unnecessary hospital admissions and visits to emergency departments, ${ }^{7}$ leading to substantial costs for health care and a negative effect on quality of life. ${ }^{8}$

Observational evidence suggests that frailty involves a slowly progressive functional deterioration over five to 10 years ${ }^{9}$ during which there are many opportunities for early recognition and intervention. Improved knowledge and practical case finding strategies would allow clinicians to provide better support for their patients who are living with or who are at risk of frailty better and, therefore, at increased risk of declining health and loss of independence.

We review the utility of validated instruments for case finding and identifying frailty components, as well as evidence for interventions to prevent or reverse frailty (Box 1) and consider the application of this evidence in the nonspecialist setting.

Box 1: Evidence used in this review.

This review was informed by clinical experience, best practice guidelines and literature review. We searched PubMed using combinations of the following terms: "frail elderly," "frailty,"

"identification," "screening," "assessment," "management," "interventions," "guidelines," "consensus," "definition" and "natural history." In addition, we reviewed relevant papers retrieved from the reference lists of selected articles. We limited our search to articles published in English since 2001, when two seminal papers by Fried and colleagues ${ }^{10}$ and Rockwood and colleagues ${ }^{11}$ were published. We included 78 articles that were most relevant to the goals of this review, with emphasis placed on more recent publications. We focused on consensus statements, best practice guidelines, systematic reviews, meta-analyses, scoping reviews, randomized controlled trials and evidence relevant to the Canadian context.

\section{KEY POINTS}

- Frailty is a state of increased vulnerability to negative health outcomes that manifest as a multidimensional syndrome; it has gained recognition as a priority for health care systems.

- The impacts of frailty warrant an upstream, proactive, holistic, interprofessional primary care approach to its identification, assessment and management.

- Identifying frailty at an earlier stage can be challenging and is best complemented with the use of valid, reliable tools that are also feasible in the busy primary care setting.

- Multicomponent interventions for management of frailty should be based on the patient's health needs, priorities and level of frailty, with involvement of various team members.

- An effective multicomponent approach may include care and support planning, physical activity, dietary interventions, structured medication reviews and strengthening social networks.

\section{What are the many dimensions of frailty?}

A recent scoping review tackled the previous lack of consensus on a single view of frailty and offered a working definition that provides clinicians with a pragmatic understanding of the complex and multidimensional nature of frailty as having psychological, cognitive and social aspects in addition to physical characteristics. ${ }^{12}$ Understanding that frailty involves complex interactions between biopsychosocial factors ${ }^{13}$ will require that clinicians shift from a traditional disease-based approach to a multidimensional model.

Physical frailty is well-defined and characterized by reduced physiologic function. Based on the frailty phenotype model, ${ }^{10}$ its features include unintentional weight loss, self-reported exhaustion, weakness, slow walking speed and low physical activity. This model is anchored in a physiologic model that postulates dysregulated energy metabolism, and both cellular and molecular mechanisms, as summarized elsewhere. ${ }^{14}$ Here, physical frailty is defined as an important medical syndrome that is clinically meaningful and distinct from disability. ${ }^{15}$ 
Other aspects of frailty that substantially affect a person's wellbeing and independence have not been explored extensively. ${ }^{16}$ Psychological frailty involves a loss of resilience in cognitive, mood and motivational components. ${ }^{17}$ Cognitive frailty has been recognized recently as a distinct clinical concept of simultaneous physical frailty and cognitive impairment in the absence of concurrent dementia. ${ }^{18,19}$ In this context, cognitive impairment appears to be related to physical causes and has the potential for reversibility. ${ }^{18}$ Even social frailty, defined as the loss of social resources and behaviours that are important for an individual's social needs, ${ }^{20}$ may be placed within the frailty construct.

In its 2015 report on healthy aging, the World Health Organization proposed the concept of "intrinsic capacity" as a way to define healthy aging in functional rather than disease-based terms. ${ }^{21}$ Like multidimensional frailty, intrinsic capacity captures physical, cognitive, psychological and sensory domains. Resilience, sometimes considered to be the opposite of frailty, would then represent, in functional terms, the dynamic interaction between intrinsic capacity and the social domain, with its external resources or stressors. The framing of frailty and intrinsic capacity are in fact complementary. Seeking to maintain patients' intrinsic capacity, strengthening their resilience and mitigating frailty may be the main role of the primary care physician who is caring for patients at risk of frailty.

\section{Why does frailty matter?}

Frailty is common in the last year of life; it is more common than other disease-oriented patterns such as organ failure, dementia and cancer. ${ }^{5}$ Furthermore, it has an incremental effect on survival, institutionalization and other adverse outcomes among patients admitted to intensive care, ${ }^{22}$ undergoing cardiac surgery, ${ }^{23}$ and diagnosed with cancer ${ }^{24}$ or heart failure..$^{25}$ It consumes substantial health and social care resources driven by inpatient, pharmaceutical ${ }^{26}$ and long-term care ${ }^{27}$ costs. Given its negative effect on individuals and their families, society and the health care system, and considering that the number of older Canadians is rising, ${ }^{28}$ frailty presents a serious public health concern, in particular because it is usually recognized after its onset. ${ }^{29}$ Therefore, primary care physicians and generalists require the tools to be able to identify and address frailty in everyday practice. ${ }^{30}$

Early recognition of frailty in primary care can help shape appropriate care processes that are tailored to the needs of older adults living with frailty, ${ }^{31}$ and prompt conversations with patients about their goals, preferences and priorities for care as might happen on diagnosis of a life-limiting illness. ${ }^{26,32}$ Such conversations can offer patients choices in line with their objective level of frailty and mitigate against age discrimination for older adults who are not frail. ${ }^{1}$ For example, this may mean exploring less invasive options, or anticipating or mitigating potential adverse events while proceeding with treatment.

\section{When and how should frailty be identified?}

Any consultation between an older adult and health care providers represents an opportunity to identify frailty and recognize care needs as outlined in 2014 guidance from the British Geriatrics Society. ${ }^{33}$ Given that earlier stages of frailty can be difficult for clinicians to differentiate from normal aging, valid and acceptable tools may be used to augment clinical impression. Despite the complexity of frailty and the inherent challenges in developing and validating an acceptable frailty instrument, many good candidate measures have emerged.

A systematic review of diagnostic accuracy of simple instruments for identifying frailty in community-dwelling older adults identified several clinician-oriented case finding tools with good diagnostic accuracy that go beyond chronological age or sex. ${ }^{34}$ However, settings and populations seem to influence instrument performance. A recent study that compared 35 published frailty scales found marked heterogeneity in frailty classification and prevalence. ${ }^{35}$ In a busy primary care setting, besides validity and reliability, other factors such as ease of use (based on time, training and equipment) and need for added resources for tool administration (Table 1) may affect a practitioner's choice of frailty measures. Some of the common tools used in clinical practice are judgment-based tools (e.g., the Clinical Frailty Scale), physical performance tools (e.g., Gait Speed), patient questionnaires (e.g., Program of Research to Integrate the Services for the Maintenance of Autonomy [PRISMA-7]), the electronic Frailty Index and multidimensional measures (e.g., Edmonton Frail Scale).

The British Geriatrics Society recommends that clinicians use the PRISMA-7 questionnaire, Gait Speed (4-metre walk) test and timed-up-and-go test as simple measures. ${ }^{33}$ In the diagnostic accuracy review, ${ }^{34}$ the PRISMA-7 questionnaire, timed-up-and-go test and the Gait Speed test were shown to have high sensitivity (83\%, 93\% and 99\%, respectively) but low specificity (83\%, 62\% and $64 \%$, respectively). Low specificity increases the risk of falsepositive results and questions the value of using these simple tools in patients identified through case finding who are not subsequently assessed carefully to confirm frailty or its components. An 2012 systematic review ${ }^{47}$ recommended the Tilburg Frailty Indicator and the Survey of Health, Aging and Retirement in Europe Frailty Instrument (SHARE-FI) as potential suitable tools for identifying frailty among adults who are 50 years of age or older in the primary care setting, despite the limitations of the tools and need for large validation studies in this setting.

A 2011 systematic review ${ }^{48}$ identified the Frailty Index as the most suitable instrument to be used as an evaluative outcome measure in frailty research. Although the Frailty Index has shown good criterion and construct validity, ${ }^{45}$ it is more commonly used in research settings than in clinical practice because the amount of information required to calculate the score appears daunting to those without training in geriatric medicine. ${ }^{49}$ However, this could be overcome by using readily available information in electronic medical records. Constructing an electronic Frailty Index is a practical, time-efficient, valid and sensitive way to target older adults at risk of frailty. ${ }^{43}$ This approach has been implemented in the United Kingdom ${ }^{50}$ as a successful strategy for identifying point-of-care frailty in primary care; however, this type of system is not in place in Canada at this time.

Some of the available multidimensional tools can be used for both case finding and component definition (i.e., exploring the 
components of frailty such as cognitive ability, multimorbidity, functional status and mobility, polypharmacy, social supports, continence and mood). An example of a tool that was created in Canada is the Edmonton Frail Scale. This scale does not require specialized equipment and can be done in less than 10 minutes by any trained practitioner.
The spectrum of fitness and frailty in a primary care population makes it challenging to apply screening systematically based on an arbitrary age cut point. Not only might this be needlessly resource intensive, but it might also be objectionable to many older adults who are not frail. Therefore, if risk factors for frailty are present (e.g., advanced age, functional compromise,

\section{Table 1 (part 1 of 2): Selected frailty measures for the primary care setting}

\begin{tabular}{|c|c|c|c|c|c|c|}
\hline Tool & Type & Components examined & Frailty scoring system & $\begin{array}{l}\text { Psychometric } \\
\text { properties }\end{array}$ & $\begin{array}{l}\text { Time to } \\
\text { complete, } \\
\text { min }\end{array}$ & $\begin{array}{c}\text { Tool administered } \\
\text { by }\end{array}$ \\
\hline Clinical Frailty Scale & Judgment based & $\begin{array}{l}\text { Visual chart of nine pictures } \\
\text { covering the frailty spectrum, } \\
\text { with corresponding } \\
\text { explanation text. }\end{array}$ & $\begin{array}{l}\text { Nine grades of frailty from } \\
1 \text { (very fit) to } 9 \text { (terminally } \\
\text { ill). A score of } 5 \text { or more } \\
\text { indicates frailty. }\end{array}$ & $\begin{array}{l}\text { Predictive } \\
\text { validity and } \\
\text { reliability }^{36}\end{array}$ & $<5$ & $\begin{array}{l}\text { Physicians or } \\
\text { practice nurses }\end{array}$ \\
\hline Gait Speed & Performance based & $\begin{array}{l}\text { Patient is asked to walk from } \\
\text { one place to another at usual } \\
\text { speed. Distance considered } \\
\text { ranges from } 2.4 \text { to } 6 \mathrm{~m} \text {. }\end{array}$ & $\begin{array}{l}\text { A walking speed of } \\
<0.8 \mathrm{~m} / \mathrm{s} \text { identifies patients } \\
\text { at high risk of frailty. }\end{array}$ & $\begin{array}{l}\text { Diagnostic test } \\
\text { accuracy }^{34}\end{array}$ & $<5$ & $\begin{array}{l}\text { Physicians or } \\
\text { practice nurses }\end{array}$ \\
\hline Timed-up-and-go test & Performance based & $\begin{array}{l}\text { The test measures the time } \\
\text { taken to stand up from a chair, } \\
\text { walk a distance of } 3 \mathrm{~m} \text {, turn, } \\
\text { walk back and sit down. }\end{array}$ & $\begin{array}{l}\text { A time of }>10 \text { s identifies } \\
\text { patients at risk of frailty. }\end{array}$ & $\begin{array}{l}\text { Diagnostic test } \\
\text { accuracy }^{37}\end{array}$ & $<5$ & $\begin{array}{l}\text { Physicians or } \\
\text { practice nurses }\end{array}$ \\
\hline FRAIL & Questionnaire & $\begin{array}{l}\text { Five items with yes/no } \\
\text { answers: } \\
\text { - Fatigue } \\
\text { - Resistance (ability to climb } \\
\text { up one flight of stairs) } \\
\text { - Ambulation (ability to } \\
\text { walk one block) } \\
\text { - Illness (> } 5 \text { comorbidities) } \\
\text { - Loss of weight (> } 5 \%)\end{array}$ & $\begin{array}{l}\text { Frailty: three or more } \\
\text { components present } \\
\text { Prefrailty: one to two } \\
\text { components present } \\
\text { Robust: zero components } \\
\text { present }\end{array}$ & $\begin{array}{l}\text { Convergent and } \\
\text { predictive } \\
\text { validity }^{38}\end{array}$ & $<5$ & $\begin{array}{l}\text { Physicians, practice } \\
\text { nurses, or patients } \\
\text { or their family } \\
\text { members }\end{array}$ \\
\hline $\begin{array}{l}\text { Groningen Frailty } \\
\text { Indicator }\end{array}$ & Questionnaire & $\begin{array}{l}\text { Fifteen-item clinician- } \\
\text { administered questionnaire } \\
\text { concerning four domains: } \\
\text { physical, social, } \\
\text { psychological and cognitive. }\end{array}$ & Frailty: scores $>4$ & $\begin{array}{l}\text { Construct } \\
\text { validity }^{39}\end{array}$ & 15 & $\begin{array}{l}\text { Physicians or } \\
\text { practice nurses }\end{array}$ \\
\hline PRISMA-7 & Questionnaire & $\begin{array}{l}\text { Seven-item self-completed } \\
\text { questionnaire with yes or } \\
\text { no answers that covers ADL } \\
\text { limitations, age (> } 85 \mathrm{yr} \text { ) } \\
\text { and sex }\end{array}$ & $\begin{array}{l}\text { Frailty: three or more } \\
\text { components present }\end{array}$ & $\begin{array}{l}\text { Diagnostic test } \\
\text { accuracy }^{34}\end{array}$ & $<5$ & Self-administered \\
\hline $\begin{array}{l}\text { Tilburg Frailty } \\
\text { Indicator }\end{array}$ & Questionnaire & $\begin{array}{l}\text { Contains two parts: } 10 \\
\text { questions on determinants } \\
\text { of frailty and diseases (Part } \\
\text { A) and } 15 \text { questions on } \\
\text { components of frailty in } \\
\text { three domains (i.e., physical, } \\
\text { psychologic and social } \\
\text { frailty) (Part B) }\end{array}$ & $\begin{array}{l}\text { A score of } 5 \text { or more } \\
\text { indicates frailty. }\end{array}$ & $\begin{array}{l}\text { Reliability, } \\
\text { construct, } \\
\text { predictive and } \\
\text { concurrent types } \\
\text { of validity }{ }^{40}\end{array}$ & $<15$ & Self-administered \\
\hline Frailty phenotype & $\begin{array}{l}\text { Mixed } \\
\text { (questionnaire and } \\
\text { performance based) }\end{array}$ & $\begin{array}{l}\text { Five items with yes or no } \\
\text { answers: } \\
\text { - Weight loss over the past } \\
\text { year ( } \geq 4.5 \mathrm{~kg} \\
\text { unintentionally) } \\
\text { - Slow walking speed } \\
\text { - Low grip strength } \\
\text { - Exhaustion (two self- } \\
\text { reported questions) } \\
\text { - Low physical activity }\end{array}$ & $\begin{array}{l}\text { Frailty: three or more } \\
\text { components present } \\
\text { Prefrailty: one or two } \\
\text { components present } \\
\text { Robust: no components } \\
\text { present }\end{array}$ & $\begin{array}{l}\text { Concurrent and } \\
\text { predictive } \\
\text { validity }^{10}\end{array}$ & $15-20$ & $\begin{array}{l}\text { Physicians or } \\
\text { practice nurses }\end{array}$ \\
\hline
\end{tabular}




\begin{tabular}{|c|c|c|c|c|c|c|}
\hline Tool & Type & Components examined & Frailty scoring system & $\begin{array}{l}\text { Psychometric } \\
\text { properties }\end{array}$ & $\begin{array}{l}\text { Time to } \\
\text { complete, } \\
\text { min }\end{array}$ & $\begin{array}{c}\text { Tool administered } \\
\text { by }\end{array}$ \\
\hline $\begin{array}{l}\text { SHARE Frailty } \\
\text { Instrument (SHARE-FI) }\end{array}$ & $\begin{array}{l}\text { Mixed } \\
\text { (questionnaire and } \\
\text { performance based) }\end{array}$ & $\begin{array}{l}\text { Includes five variables: } \\
\text { exhaustion, weight loss, } \\
\text { weakness (as assessed by } \\
\text { handgrip strength using a } \\
\text { dynamometer), slowness } \\
\text { and low activity }\end{array}$ & $\begin{array}{l}\text { Web-based calculator } \\
\text { distinguishes three } \\
\text { categories: nonfrail, prefrail } \\
\text { and frail }\end{array}$ & $\begin{array}{l}\text { Construct and } \\
\text { predictive } \\
\text { validity }^{41}\end{array}$ & $<10$ & $\begin{array}{l}\text { Nonphysicians (e.g., } \\
\text { nurses, allied health } \\
\text { professionals) }\end{array}$ \\
\hline $\begin{array}{l}\text { Study of Osteoporotic } \\
\text { Fractures }\end{array}$ & $\begin{array}{l}\text { Mixed } \\
\text { (Questionnaire and } \\
\text { performance based) }\end{array}$ & $\begin{array}{l}\text { Three items with yes or no } \\
\text { answers: } \\
\text { - Weight loss (> 5\% } \\
\text { intentional/unintentional) } \\
\text { - Exhaustion (Do you feel } \\
\text { full of energy?) } \\
\text { - Inability to rise from a } \\
\text { chair five times without } \\
\text { using arms }\end{array}$ & $\begin{array}{l}\text { Frailty: one or more } \\
\text { components present } \\
\text { Prefrailty: one component } \\
\text { present } \\
\text { Robust: No components } \\
\text { present }\end{array}$ & $\begin{array}{l}\text { Predictive } \\
\text { validity }^{42}\end{array}$ & $<5$ & $\begin{array}{l}\text { Physicians or } \\
\text { practice nurses }\end{array}$ \\
\hline $\begin{array}{l}\text { Electronic Frailty } \\
\text { Index }\end{array}$ & Data set & $\begin{array}{l}\text { As per the Frailty Index } \\
\text { below, with variables } \\
\text { obtained from primary } \\
\text { care electronic medical } \\
\text { records }\end{array}$ & $\begin{array}{l}\text { Severe frailty: a score of } \\
>0.36 \\
\text { Frailty: a score of } 0.24- \\
0.36 \\
\text { Mild frailty: a score of } \\
0.12-0.24 \\
\text { Fit: a score of } \leq 0.12\end{array}$ & $\begin{array}{l}\text { Predictive } \\
\text { validity }^{43}\end{array}$ & $\begin{array}{l}\quad<5 \\
\text { (if automated) }\end{array}$ & $\begin{array}{l}\text { Automatically } \\
\text { computed from } \\
\text { the electronic } \\
\text { medical records }\end{array}$ \\
\hline Frailty Index & Data set & $\begin{array}{l}\text { Any } 30 \text { or more health } \\
\text { deficits (variables) that } \\
\text { increase in prevalence with } \\
\text { age but do not plateau } \\
\text { with age. Variables should } \\
\text { be multidimensional, } \\
\text { including ADLs/IADLs, } \\
\text { comorbidities, mood, } \\
\text { cognition and nutritional } \\
\text { status. }\end{array}$ & $\begin{array}{l}\text { Frailty is measured on a } \\
\text { continuum, although } \\
>0.25 \text { is often selected } \\
\text { to define frailty. }{ }^{44}\end{array}$ & $\begin{array}{l}\text { Criterion and } \\
\text { construct } \\
\text { validity }{ }^{45}\end{array}$ & $20-30$ & $\begin{array}{l}\text { Mostly } \\
\text { administered by } \\
\text { researchers; } \\
\text { further use in } \\
\text { clinical practice } \\
\text { needs to be } \\
\text { explored }\end{array}$ \\
\hline $\begin{array}{l}\text { Edmonton Frail } \\
\text { Scale }\end{array}$ & Multidimensional & $\begin{array}{l}\text { Nine items: cognition, } \\
\text { health (two items), } \\
\text { admission to hospital, } \\
\text { social support, nutrition, } \\
\text { mood, function and } \\
\text { continence }\end{array}$ & Frailty: score $>7$ & $\begin{array}{l}\text { Construct validity } \\
\text { and reliability }{ }^{46}\end{array}$ & $<10$ & $\begin{array}{l}\text { Physicians or } \\
\text { practice nurses }\end{array}$ \\
\hline
\end{tabular}

Note: $A D L=$ activities of daily living, IADL = instrumental activities of daily living, PRISMA-7 = Program of Research to Integrate the Services for the Maintenance of Autonomy, SHARE = Survey of Health, Aging and Retirement in Europe.

*The Electronic Frailty Index is easy to use once it is automated in the electronic medical records; however, if done manually, it requires time and training.

polypharmacy, poor nutrition, weight loss, or medical and psychiatric comorbidities), ${ }^{51}$ clinicians could apply a rapid case finding test first, such as the Clinical Frailty Scale, Gait Speed or PRISMA-7. This approach respects the busy nature of primary care practice and forms the foundation for a more intensive approach that can better discriminate frailty components and severity (e.g., by using a multidimensional measure such as Edmonton Frail Scale).

Based on the complexity and severity of frailty uncovered by these tools, primary health care teams can design targeted interventions to address the components of frailty (e.g., fall risk reduction or structured medication review) or determine whether referral to a specialist in geriatric medicine for a more in-depth frailty assessment (i.e., comprehensive geriatric assessment) is warranted.

\section{How can frailty be managed?}

Primary care clinicians and teams are not likely to engage in frailty case finding or use multidimensional tools unless they can offer useful evidence-based recommendations to their patients. However, evidence for interventions that can prevent, delay and treat frailty remains limited.

From a population perspective, preventing or delaying onset of frailty would be most beneficial. A recent systematic review examined interventions to prevent prefrailty and progression of frailty in older adults but did not find a clearly effective population-based strategy. ${ }^{52}$ Current strategies either target individuals who are frail within a mixed population or try to ensure 
that care protocols are appropriately tailored in a population with a high prevalence. Research is ongoing in this area in the form of a comprehensive review of more than 200 randomized controlled trials (RCTs), which is funded by the Canadian Frailty Network, to develop a set of standardized core data elements and common outcomes in frailty research. ${ }^{53}$

Until more sound evidence is available, we suggest implementing a person-centred approach in all individuals who live with frailty. Individuals identified as frail or at high risk of frailty should be advised, according to individual circumstances, on care and support planning, exercise, nutrition, medication reviews and the need to strengthen social networks. The multidimensional and heterogeneous nature of frailty necessitates therapeutic approaches that have multiple components, ${ }^{54}$ ideally accomplished through a collaborative and interdisciplinary approach in the community, and precisely oriented to the component needs and circumstances of the individual who is frail. We suggest that those with severe frailty or challenging geriatric syndromes be referred for assessment by an appropriate geriatric specialist (Box 2).

\section{Supportive care}

Care and support planning can be delivered in many ways: in general, it involves a discussion among patients, family members and health care providers as equals. Topics that are discussed include the goals and priorities of the patients and caregivers, required supports, self-management, preferences for end-of-life care and other aspects relevant to the needs of a particular patient and their family members..$^{55} \mathrm{~A}$ good example is the Palliative and Therapeutic Harmonization Program (PATH), which is a consultative resource by which multidimensional frailty criteria can be employed to inform appropriate future care planning. ${ }^{56}$

\section{Interventions involving physical activity}

A recent scoping review of studies of interventions to prevent or reduce the level of frailty in community-dwelling older adults showed that interventions involving physical activity (including those involving strength, balance, coordination, flexibility and aerobic exercise) and prehabilitation (i.e., physical therapy in combination with exercise and modifications to the home before a planned intervention) mostly reduced the number of frailty markers present and, consequently, the prevalence of frailty. ${ }^{12}$ Several systematic reviews and meta-analyses have shown that multicomponent interventions, with physical activity as one of the components, can reverse frailty, ${ }^{57}$ improve physical function and performance of activities of daily living, ${ }^{58}$ decrease falls and improve gait, balance and strength performance..$^{59} \mathrm{~A}$ recent RCT also showed that physical activity had positive effects on cognition, emotional and social networking. ${ }^{60}$ Despite this strong evidence behind physical activity, proposed by some authors as a "lifelong physiologic supplement" in frailty prevention and management, ${ }^{61}$ more research is needed to outline the optimal program in terms of its components, duration and setting. ${ }^{57}$

\section{Nutritional support}

Malnutrition and frailty were shown to be strongly associated in a 2017 systematic review. ${ }^{62}$ Although none of the included studies were prospective in nature, increased protein intake and
Box 2: Building frailty into the workflow of primary care

- Select a frailty case finding tool and start using it in your practice.

- Use frailty status to open a personalized discussion with the patient about advanced care planning.

- Build the capacity of your primary care team members and local resources and programs to customize their approach based on identified components of frailty, supplemented by use of a multidimensional tool.

- Implement a multicomponent approach to care that includes attention to exercise, nutrition, medications and social networks in the care of all individuals who live with frailty.

- Define and act on triggers that require the aid of geriatrician specialists.

dietary quality appeared to be protective factors against frailty. Combined with exercise, dietary interventions may also prove to be an important part of a multimodal approach to prevent and treat frailty, but further evidence is required. ${ }^{63}$

\section{Medication review}

Polypharmacy is common among older adults who are frail and is associated with increased risk of predictable and preventable adverse drug events. ${ }^{64}$ Accumulation of chronic conditions, inappropriate prescribing, suboptimal monitoring of drugs, and agerelated changes in pharmacokinetics and pharmacodynamics compound the problem. ${ }^{65} \mathrm{~A}$ structured medication review guided by the screening tool for older peoples' prescriptions (STOPP), the screening tool to alert to right treatment (START) ${ }^{66}$ or the American Geriatrics Society Beers ${ }^{67}$ criteria for frailty management is currently recommended by several guidelines, including the best practice guidelines from the British Geriatrics Society, Age UK and the Royal College of General Practitioners, ${ }^{68}$ and the Asia-Pacific clinical practice guidelines. ${ }^{69}$

\section{Addressing social vulnerability}

Social isolation has been shown to affect the overall health and survival of older adults in Canada, ${ }^{70,71}$ and there is a graded association with frailty. ${ }^{72}$ However, evidence to support strategies to address social risk in the management of frailty or its adverse outcomes is lacking. ${ }^{70-72}$

\section{Geriatric assessment}

A comprehensive geriatric assessment is the current gold standard for identifying frailty and guiding management of those who are frail; 68 a comprehensive geriatric assessment comprises multidimensional assessments to determine the medical, functional, social and psychological aspects of an older adult living with frailty. Randomized trials evaluating assessment intervention programs for frailty in community-dwelling older adults have shown that, with high adherence to initiated interventions, comprehensive geriatric assessments can delay progression of frailty, reduce mortality, increase the odds of staying at home and decrease unplanned admissions to hospital. ${ }^{73-77}$ Application of this evidence (i.e., deciding which older adults would benefit from a particular intervention or intervention component) is challenging. However, 


\section{Box 3: Gaps in the literature}

- Future intervention studies should not be limited to physical function, but should include other components that target nutritive, cognitive, social and psychological frailty separately and in combination.

- Future research needs to consider patient-centred outcomes rather than just the traditional clinical outcomes.

- Cost-effectiveness of models of care from well-executed economic evaluations in large-scale studies with longer intervention and follow-up periods is needed to promote and scale up effective models.

careful interrogation of frailty components followed by personalized care and support planning will help practitioners to tailor frailty management to individual patients. When selecting an intervention for an older adult with frailty, it is important to elicit the patient's goals and priorities and consider the benefit-toharm ratio based on the severity of frailty.

\section{Conclusion}

Although many may point to uncertain benefits of frailty case finding in the primary care setting as a reason not to address frailty at the population level, the increasing prevalence of frailty, its contribution to mounting health care costs, and its impact on quality of life in older adults suggest that early identification and management are prudent even if some important research questions remain unanswered (Box 3 ). The current availability of validated instruments for both case finding and identifying frailty components moves health care providers beyond theory into practical application in the most appropriate settings. Specifically, this complex phenomenon should be identified, assessed and managed by health care providers beyond geriatric medicine, and primary care physicians are optimally suited to achieve these goals because of primary care's comprehensive, personcentred and team-based approach.

\section{References}

1. Clegg A, Young J, Iliffe S, et al. Frailty in elderly people. Lancet 2013;381:752-62.

2. Hoover M, Rotermann M, Sanmartin C, et al. Validation of an index to estimate the prevalence of frailty among community-dwelling seniors. Health Rep 2013;24:10-17.

3. Xue Q-L. The frailty syndrome: definition and natural history. Clin Geriatr Med 2011;27:1-15

4. Poli S, Cella A, Puntoni M, et al. Frailty is associated with socioeconomic and lifestyle factors in community-dwelling older subjects. Aging Clin Exp Res 2017; 29:721-8.

5. Gill TM, Gahbauer EA, Han L, et al. Trajectories of disability in the last year of life. N Engl J Med 2010;362:1173-80.

6. Panza F, Lozupone M, Solfrizzi V, et al. Different cognitive frailty models and health-and cognitive-related outcomes in older age: from epidemiology to prevention. J Alzheimers Dis 2018;62:993-1012.

7. Di Pollina L, Guessous I, Petoud V, et al. Integrated care at home reduces unnecessary hospitalizations of community-dwelling frail older adults: a prospective controlled trial. BMC Geriatr 2017;17:53.

8. Landi F, Cesari M, Onder G, et al. Physical activity and mortality in frail, communityliving elderly patients. J Gerontol A Biol Sci Med Sci 2004;59:833-7.

9. Covinsky KE, Eng C, Lui L, et al. The last 2 years of life: functional trajectories of frail older people. J Am Geriatr Soc 2003;51:492-8.
10. Fried LP, Tangen CM, Walston J, et al. Frailty in older adults: evidence for a phenotype. J Gerontol A Biol Sci Med Sci 2001;56:146-57.

11. Mitnitski AB, Mogilner AJ, Rockwood K. Accumulation of deficits as a proxy measure of aging. Sci World J 2001;1:323-36.

12. Puts MT, Toubasi S, Andrew MK, et al. Interventions to prevent or reduce the level of frailty in community-dwelling older adults: a scoping review of the literature and international policies. Age Ageing 2017;46:383-92.

13. Roe L, Normand C, Wren M-A, et al. The impact of frailty on healthcare utilisation in Ireland: evidence from the Irish longitudinal study on ageing. BMC Geriatr 2017;17:203.

14. Walston J, Hadley EC, Ferrucci L, et al. Research agenda for frailty in older adults: toward a better understanding of physiology and etiology: summary from the American Geriatrics Society/National Institute on Aging Research Conference on Frailty in Older Adults. J Am Geriatr Soc 2006;54:991-1001.

15. Morley JE, Vellas B, van Kan GA, et al. Frailty consensus: a call to action. J Am Med Dir Assoc 2013;14:392-7.

16. van Oostrom SH, Rietman ML, Picavet HSJ, et al. A four-domain approach of frailty explored in the Doetinchem Cohort Study. BMC Geriatr 2017;17:196.

17. Fitten LJ. Psychological frailty in the aging patient. In: Frailty: pathophysiology, phenotype and patient care. Basel (Switzerland): Karger Publishers; 2015:45-54.

18. Panza F, Lozupone M, Solfrizzi V, et al. Cognitive frailty: a potential target for secondary prevention of dementia. 2017;13:1023-7.

19. Kelaiditi E, Cesari M, Canevelli M, et al. Cognitive frailty: rational and definition from an (IANA/IAGG) international consensus group. J Nutr Health Aging 2013;17:726-34.

20. Bunt S, Steverink N, Olthof J, et al. Social frailty in older adults: a scoping review. Eur J Ageing 2017;14:323-34.

21. Integrated care for older people: guidelines on community-level interventions to manage declines in intrinsic capacity. Geneva: World Health Organization; 2017. Available: http://apps.who.int/iris/bitstream/10665/258981/1/9789241550109-eng. pdf?ua=1 (accessed 2017 Nov. 20).

22. Muscedere J, Waters B, Varambally A, et al. The impact of frailty on intensive care unit outcomes: a systematic review and meta-analysis. Intensive Care Med 2017:43:1105-22.

23. Sepehri A, Beggs T, Hassan A, et al. The impact of frailty on outcomes after cardiac surgery: a systematic review. J Thorac Cardiovasc Surg 2014;148:3110-7.

24. Handforth C, Clegg A, Young C, et al. The prevalence and outcomes of frailty in older cancer patients: a systematic review. Ann Oncol 2015;26:1091-101.

25. Jha SR, Ha HS, Hickman LD, et al. Frailty in advanced heart failure: a systematic review. Heart Fail Rev 2015;20:553-60

26. Bock J-O, König $\mathrm{H}-\mathrm{H}$, Brenner $\mathrm{H}$, et al. Associations of frailty with health care costs - results of the ESTHER cohort study. BMC Health Serv Res 2016;16:128.

27. Peters LL, Burgerhof JG, Boter $\mathrm{H}$, et al. Predictive validity of a frailty measure (GFI) and a case complexity measure (IM-E-SA) on healthcare costs in an elderly population. J Psychosom Res 2015;79:404-11.

28. Estimates of population, by age group and sex for July 1, Canada, provinces and territories. Ottawa: Statistics Canada. Available: www5.statcan.gc.ca/cansim/ a26?lang=eng\&retrLang=eng\&id=0510001\&\&pattern $=\&$ stByVal $=1 \& p 1=1 \& p 2=37 \&$ tabMode $=$ dataTable \&csid $=$ (accessed 2018 May 18).

29. Ko FC-Y. The clinical care of frail, older adults. Clin Geriatr Med 2011;27:89-100.

30. Cesari M, Prince M, Thiyagarajan JA, et al. Frailty: an emerging public health priority. J Am Med Dir Assoc 2016;17:188-92.

31. Holroyd-Leduc J, Resin J, Ashley L, et al. Giving voice to older adults living with frailty and their family caregivers: engagement of older adults living with frailty in research, health care decision making, and in health policy. Res Involv Engagem 2016;2:23.

32. Maida V, Devlin M. Frailty, thy name is Palliative! CMAJ 2015;187:1312.

33. Fit for frailty. Consensus best practice guidance for the care of older people living with frailty in community and outpatient settings. London (UK): British Geriatrics Society; 2017. Available: www.bgs.org.uk/sites/default/files/content/ resources/files/2018-05-23/fff_full.pdf (accessed 2018 Aug. 17).

34. Clegg A, Rogers L, Young J. Diagnostic test accuracy of simple instruments for identifying frailty in community-dwelling older people: a systematic review. Age Ageing 2015;44:148-52.

35. Aguayo GA, Donneau A-F, Vaillant MT, et al. Agreement between 35 published frailty scores in the general population. Am J Epidemiol 2017;186:420-34.

36. Rockwood K, Song X, Macknight C, et al. A global clinical measure of fitness and frailty in elderly people. CMAJ 2005;173:489-95.

37. Savva GM, Donoghue OA, Horgan F, et al. Using timed up-and-go to identify frail members of the older population. J Gerontol A Biol Sci Med Sci 2013;68:441-6.

38. Morley JE, Malmstrom T, Miller D. A simple frailty questionnaire (FRAIL) predicts outcomes in middle aged African Americans. J Nutr Health Aging 2012;16:601-8. 
39. Peters LL, Boter H, Burgerhof J, et al. Construct validity of the Groningen Frailty Indicator established in a large sample of home-dwelling elderly persons: evidence of stability across age and gender. Exp Gerontol 2015;69:129-41.

40. Gobbens RJ, van Assen MA, Luijkx KG, et al. The Tilburg Frailty Indicator: psychometric properties. J Am Med Dir Assoc 2010;11:344-55.

41. Romero-Ortuno R, Walsh CD, Lawlor BA, et al. A frailty instrument for primary care: findings from the Survey of Health, Ageing and Retirement in Europe (SHARE). BMC Geriatr 2010;10:57.

42. Bilotta $C$, Nicolini $P$, Casè $A$, et al. Frailty syndrome diagnosed according to the Study of Osteoporotic Fractures (SOF) criteria and adverse health outcomes among community-dwelling older outpatients in Italy. A one-year prospective cohort study. Arch Gerontol Geriatr 2012;54:e23-8.

43. Clegg A, Bates C, Young J, et al. Development and validation of an electronic frailty index using routine primary care electronic health record data. Age Ageing 2016;45:353-60

44. Rockwood K, Mitnitski A. Frailty in relation to the accumulation of deficits. J Gerontol A Biol Sci Med Sci 2007;62:722-7.

45. Drubbel I, Numans ME, Kranenburg G, et al. Screening for frailty in primary care: a systematic review of the psychometric properties of the frailty index in community-dwelling older people. BMC Geriatr 2014;14:27.

46. Rolfson DB, Majumdar SR, Tsuyuki RT, et al. Validity and reliability of the Edmonton Frail Scale. Age Ageing 2006;35:526-9.

47. Pialoux T, Goyard J, Lesourd B. Screening tools for frailty in primary health care: a systematic review. Geriatr Gerontol Int 2012;12:189-97.

48. De Vries NM, Staal J, Van Ravensberg C, et al. Outcome instruments to measure frailty: a systematic review. Ageing Res Rev 2011;10:104-14.

49. Li G, Thabane L, loannidis $G$, et al. Comparison between frailty index of deficit accumulation and phenotypic model to predict risk of falls: data from the global longitudinal study of osteoporosis in women (GLOW) Hamilton cohort. PLoS One 2015;10:e0120144.

50. Lansbury LN, Roberts HC, Clift E, et al. Use of the electronic Frailty Index to identify vulnerable patients: a pilot study in primary care. Br J Gen Pr 2017;67:e751-e6.

51. Frailty in older adults: early identification and management. Victoria: British Columbia Ministry of Health; and Vancouver: Doctors of BC; 2017. Available: www2.gov.bc.ca/assets/gov/health/practitioner-pro/bc-guidelines/frailty-full_ guideline.pdf (accessed 2018 Jan. 13).

52. Apóstolo J, Cooke R, Bobrowicz-Campos E, et al. Effectiveness of interventions to prevent pre-frailty and frailty progression in older adults: a systematic review. JBI Database System Rev Implement Rep 2018;16:140-232.

53. Shears M, McGolrick D, Waters B, et al. Frailty measurement and outcomes in interventional studies: protocol for a systematic review of randomised control trials. BMJ Open 2017;7:e018872.

54. Dedeyne L, Deschodt M, Verschueren S, et al. Effects of multi-domain interventions in (pre) frail elderly on frailty, functional, and cognitive status: a systematic review. Clin Interv Aging 2017;12:873.

55. Personalised care and support planning handbook: the journey to person-centred care. London (UK): National Health Service; 2016. Available: www.england.nhs.uk/ wp-content/uploads/2016/04/core-info-care-support-planning-1.pdf (accessed 2018 Aug. 17)

56. Moorhouse P, Mallery LH. Palliative and therapeutic harmonization: a model for appropriate decision-making in frail older adults. J Am Geriatr SoC 2012;60:2326-32.

57. Silva RB, Aldoradin-Cabeza H, Eslick G, et al. The effect of physical exercise on frail older persons: a systematic review. J Frailty Aging 2017;6:91-6.
58. Chou C-H, Hwang C-L, Wu Y-T. Effect of exercise on physical function, daily living activities, and quality of life in the frail older adults: a meta-analysis. Arch Phys Med Rehabil 2012;93:237-44.

59. Cadore EL, Rodríguez-Mañas L, Sinclair A, et al. Effects of different exercise interventions on risk of falls, gait ability, and balance in physically frail older adults: a systematic review. Rejuvenation Res 2013;16:105-14.

60. Tarazona-Santabalbina FJ, Gómez-Cabrera MC, Pérez-Ros P, et al. A multicomponent exercise intervention that reverses frailty and improves cognition, emotion, and social networking in the community-dwelling frail elderly: a randomized clinical trial. J Am Med Dir Assoc 2016;17:426-33.

61. Viña J, Rodriguez-Mañas L, Salvador-Pascual A, et al. Exercise: the lifelong supplement for healthy ageing and slowing down the onset of frailty. J Physiol 2016;594:1989-99.

62. Lorenzo-López L, Maseda A, de Labra C, et al. Nutritional determinants of frailty in older adults: a systematic review. BMC Geriatr 2017;17:108.

63. Cruz-Jentoft AJ, Kiesswetter E, Drey M, et al. Nutrition, frailty, and sarcopenia. Aging Clin Exp Res 2017;29:43-8.

64. Herr M, Robine J, Pinot J, et al. Polypharmacy and frailty: prevalence, relationship, and impact on mortality in a French sample of 2350 old people. Pharmacoepidemiol Drug Saf 2015;24:637-46.

65. Lavan AH, Gallagher P. Predicting risk of adverse drug reactions in older adults. Ther Adv Drug Saf 2016;7:11-22.

66. Lang P-O, Petrovic M, Dalleur O, et al. The exercise in applying STOPP/START. v2 in vulnerable very old patients: towards patient tailored prescribing. Eur Geriatr Med 2016;7:176-9.

67. American Geriatrics Society 2015 Beers Criteria Update Expert Panel. American Geriatrics Society 2015 updated Beers criteria for potentially inappropriate medication use in older adults. J Am Geriatr Soc 2015;63:2227-46.

68. Turner G, Clegg A. Best practice guidelines for the management of frailty: a British Geriatrics Society, Age UK and Royal College of General Practitioners report. Age Ageing 2014;43:744-7.

69. Dent E, Lien C, Lim WS, et al. The Asia-Pacific clinical practice guidelines for the management of frailty. J Am Med Dir Assoc 2017;18:564-75.

70. Andrew MK, Keefe JM. Social vulnerability from a social ecology perspective: a cohort study of older adults from the National Population Health Survey of Canada. BMC Geriatr 2014;14:90.

71. Andrew MK, Mitnitski A, Kirkland SA, et al. The impact of social vulnerability on the survival of the fittest older adults. Age Ageing 2012;41:161-5.

72. St John PD, Montgomery PR, Tyas SL. Social position and frailty. Can J Aging 2013;32:250-9.

73. Cameron ID, Fairhall N, Langron C, et al. A multifactorial interdisciplinary intervention reduces frailty in older people: randomized trial. BMC Med 2013;11:65.

74. Beswick AD, Rees K, Dieppe P, et al. Complex interventions to improve physical function and maintain independent living in elderly people: a systematic review and meta-analysis. Lancet 2008;371:725-35.

75. Thaw M, Shorthouse G, Ridgeway A, et al. Comprehensive geriatric assessment (CGA): the best integrated care approach against frailty. MOJ Gerontol Ger 2017; 1:101-3.

76. Li C-M, Chen C-Y, Li C-Y, et al. The effectiveness of a comprehensive geriatric assessment intervention program for frailty in community-dwelling older people: a randomized, controlled trial. Arch Gerontol Geriatr 2010;50:S39-42.

77. Ellis G, Whitehead MA, Robinson D, et al. Comprehensive geriatric assessment for older adults admitted to hospital: meta-analysis of randomised controlled trials. BMJ 2011;343:d6553
Competing interests: Darryl Rolfson holds the copyright for the Edmonton Frail Scale and shares licensing rights with Oxford University Press. No other competing interests were declared.

This article has been peer reviewed.

Affiliations: Faculty of Medicine and Dentistry, Departments of Medicine (Rolfson); Family Medicine (Khera, Xia), Division of Care of Elderly (Abbasi), University of Alberta; Edmonton Oliver Primary Care Network (Dabravolskaj), Edmonton, Alta.; Torrens University Australia (Dent), Adelaide, Australia; Baker Heart and Diabetes Institute (Dent), Melbourne, Australia
Contributors: Marjan Abbasi was responsible for the concept of the manuscript and outlined the literature review that was conducted by Linda Xia. Amandeep Khera and Julia Dabravolskaj drafted the manuscript with Marjan Abbasi. Darryl Rolfson added important intellectual content, and Elsa Dent was responsible for outlining the tools suitable for use in primary care. All of the authors contributed substantially to the revision of the manuscript, gave final approval of the version to be published and agreed to be accountable for all aspects of the work.

Correspondence to: Marjan Abbasi, marjan.abbasi@ albertahealthservices.ca 